\title{
Permissive Effect of Glucose on the Glucagon-Induced Accumulation of cAMP in Isolated Rat Pancreatic Islets
}

\author{
P. Schauder, J. Arends, B. Schindler, R. Ebert, and H. Frerichs \\ Department of Medicine, Division of Gastroenterology and Metabolism, University of Göttingen, Göttingen, FRG
}

Summary. Glucose stimulation increased the cAMP content of collagenase-isolated rat pancreatic islets fourfold above baseline values. The elevation was transient, lasting about $5 \mathrm{~min}$, and was dose-dependent. Insulin release continued at a constant rate throughout the incubation. - Glucagon, in the absence of glucose, increased cAMP for about $1 \mathrm{~min}$, but only slightly, and had no effect on insulin release. In the presence of glucose, however, glucagon enhanced islet cAMP content 15 -fold and increased the release of insulin. Glucagon was most effective at high glucose concentrations (16.6 and $25 \mathrm{mM})$. This indicates that glucagon is critically dependent on the presence of glucose in order to increase the islet cAMP content and to stimulate insulin release. The inability of glucagon to generate sufficient cAMP in the absence of glucose might be one of the reasons why the hormone is a potentiator rather than an initiator of insulin release.

Key words: Isolated islets, insulin release, glucagon, glucose, cyclic adenosine monophosphate.

Cyclic adenosine monophosphate (cAMP) is thought to be a main component of the stimulussecretion coupling processes involved in the release of insulin (for review see $[1,2]$ ). Positive correlations between cAMP content of islets and the rate of insulin (IRI) release after stimulation with secretagogues are usually quoted in support of this concept.

Stimulators of IRI release are either initiators or potentiators. Initiators increase rates of secretion on their own [3]. Potentiators are only effective in the presence of threshold concentrations of initiators [4-6]. It is presently undecided whether analogous differences exist between initiators and potentiators in their effects upon islet cAMP metabolism.

We therefore studied the dose-dependency and the kinetics of cAMP accumulation and of IRIrelease in isolated rat pancreatic islets stimulated by glucose (an initiator) or glucagon (a potentiator), either alone or in combination.

\section{Materials and Methods}

Male Wistar rats $\left(220-270\right.$ g), fed Altromin ${ }^{\circledR}$ and water ad libitum, were used throughout the study. Isolation of islets from pancreas was by collagenase [7] two hours after intraperitoneal administration of $0.6 \mathrm{ml}$ pilocarpine hydrochloride $(2 \% \mathrm{w} / \mathrm{v})$.

Crystalline porcine glucagon (lot 258-D30128-4) was a gift from Eli Lilly Co., Indianapolis, USA. Crystalline rat insulin was purchased from Novo Research Institute, Copenhagen, Denmark; Bovine serum albumin from Behringwerke Marburg, FRG; 125-I-porcine insulin (specific activity $150-200 \mathrm{mC} / \mathrm{mg}$ ) from Farbwerke Hoechst A.G. Frankfurt, FRG; ${ }^{3} \mathrm{H}$-cyclic-AMP (specific activity 20-30 Ci/mmole) from NEN Chemicals $\mathrm{GmbH}$, Dreieichenhain, FRG. All other reagents were analytical grade and were obtained from E.Merck A.G., Darmstadt, FRG.

To avoid contamination by non-islet tissue, islets were transferred twice to fresh Petri dishes. Prior to the experiments the islets were preincubated for 30 $\min$ in $2 \mathrm{mM}$ glucose. Batches of 20 islets were then incubated from 1 to $20 \mathrm{~min}$ in $500 \mu \mathrm{l} \mathrm{Krebs-Ringer}$ bicarbonate (KRB) buffer ( $\mathrm{pH} 7.4 ; 37^{\circ} \mathrm{C} ; 72$ cycles/ $\mathrm{min}$ ) as previously described [8], with the concentrations of glucose and glucagon indicated in the figures. $250 \mu$ lof the medium were removed $1,2.5,5$, 10 or 20 min after the start of the experiments for 


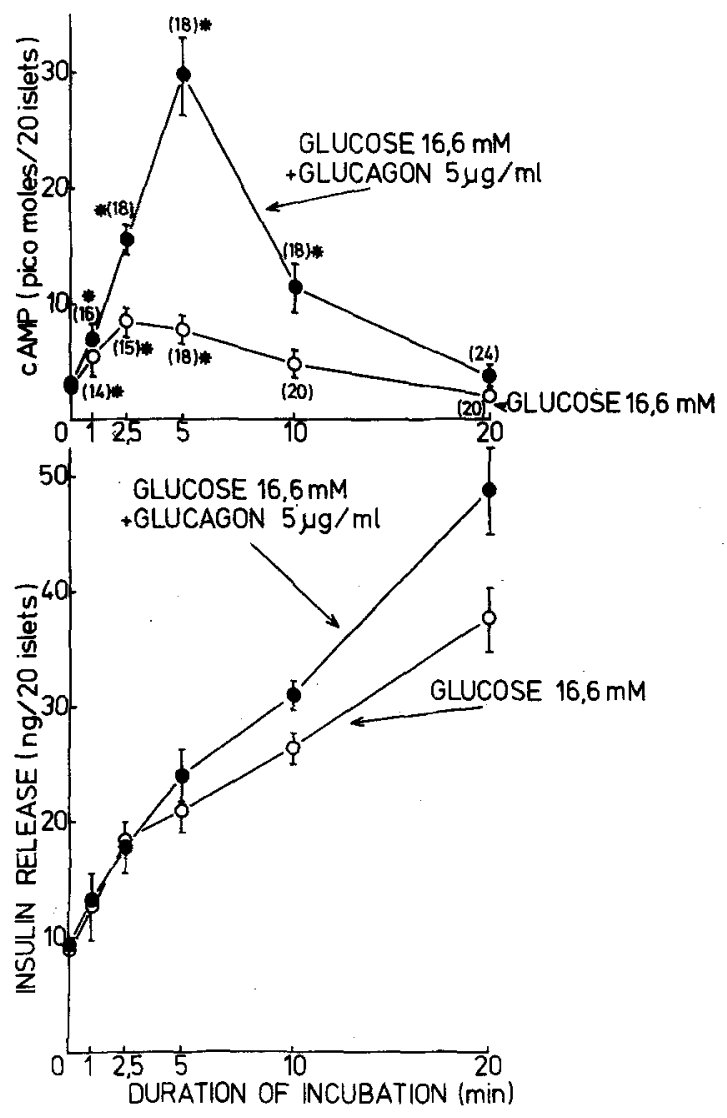

Fig. 1. Rate of insulin release and kinetics of cAMP accumulation in isolated rat pancreatic islets incubated with glucagon and/or glucose. After a $30 \mathrm{~min}$ preincubation period in the presence of 2 $\mathrm{mM}$ glucose islets were incubated for $1,2.5,10$ or $20 \mathrm{~min}$ in 500 $\mu \mathrm{l} \mathrm{KRB-buffer}$ containing $5 \mu \mathrm{g} / \mathrm{ml}$ glucagon with or without glucose $(16.6 \mathrm{mM})$. The cAMP content in the islets (pmol/20 islets) is shown in the upper panel, the IRI content of the medium in the lower panel of the figure. Mean values \pm SEM are shown, with the number of individual observations obtained from 6 to 10 pancreata in parentheses. An asterisk indicates a significant difference in the cAMP content compared with the respective zero-time control $(\mathrm{P}<0.05)$. The stimulatory effect of glucagon on glucose-induced IRI release is significant after $10 \mathrm{~min}(\mathrm{P}<$ $0.05)$ and after $20 \min (P<0.02)$

determination of insulin content by radioimmunoassay [9], with rat insulin as reference standard. The reaction was then stopped by addition of $250 \mu \mathrm{l}$ ice-cold trichloracetic acid $(7.5 \% \mathrm{w} / \mathrm{v})$ to the remaining incubation medium $(250 \mu \mathrm{l})$. After ultrasonication for 10 seconds the precipitate was removed by centrifugation and the supernatant was washed with ethyl-ether to remove the remaining trichloracetic acid. The supernatant was lyophylised to dryness, redissolved in $100 \mu \mathrm{KRB}$-buffer and assayed for cyclic AMP by the protein binding method of Gilman [10], with slight modifications [11]. Neither glucagon nor glucose interfered with the binding assay. Mean recovery of 1 pmol cyclic AMP was $94 \%$. Statistical analysis was by Student's " $t$ " test, based on nonpaired comparisons.

\section{Results}

The cyclic adenosine monophosphate content of islets incubated with $16.6 \mathrm{mM}$ glucose increased about fourfold within $2.5 \mathrm{~min}$ and declined thereaf- . ter. Basal levels were reached after $20 \mathrm{~min}$. If glucagon $(5 \mu \mathrm{g} / \mathrm{ml})$ was added with glucose cAMP levels increased about 15 fold within $5 \mathrm{~min}$ and again declined rapidly to reach basal levels after 20 minutes (Fig. 1, upper panel).

IRI content in the media increased throughout the incubations. As expected, glucagon plus glucose was more effective in stimulating IRI-release than glucose alone (Fig. 1, lower panel).

The ratio between IRI release and cAMP content was higher in glucose-treated islets than in islets incubated with glucose plus glucagon ( 2.2 vs 1.2 at $2.5 \mathrm{~min} ; 2.7$ vs 0.8 at $5 \mathrm{~min} ; 5.5$ vs 2.7 at $10 \mathrm{~min}$ and 17.9 vs 13.2 at 20 min respectively).

Figure 2 illustrates the dose-response pattern of cAMP content in islets incubated for $5 \mathrm{~min}$ with glucose $(2 ; 5 ; 8 ; 16.6$ or $25 \mathrm{mM})$ in the presence or absence of glucagon $(5 \mu \mathrm{g} / \mathrm{ml})$. The effect of glucose was dose-dependent, the minimal effective dose being about $5 \mathrm{mM}$ and the maximal effective dose being about $16.6 \mathrm{mM}$. Glucose plus glucagon was significantly more effective than glucose alone, resulting in a sigmoidal shaped curve of cAMP response. Amplification of the glucose effect by glucagon began at glucose concentrations above $2 \mathrm{mM}$ and was most pronounced at high glucose concentrations (16.6 and $25 \mathrm{mM}$ ).

No significant changes in cyclic AMP content or IRI release were observed in islets incubated up to $20 \mathrm{~min}$ in KRB-buffer. Glucagon, in the absence of glucose, caused only a small increase in the content of cAMP lasting about 1 min (Fig. 3, upper panel). This elevation was not accompanied by an increase in the release of insulin (Fig. 3, lower panel).

\section{Discussion}

Our data suggest differences in the mode of action by which glucose and glucagon stimulate cAMPgeneration in isolated rat pancreatic islets. Glucose enhances cAMP levels in a dose-dependent manner up to fourfold above baseline values (Fig. 2). This confirms recent observations [12-17], but does not agree with others $[18,19,21]$. Possible reasons for this discrepancy were previously discussed [15].

Glucagon, in the absence of glucose, leads to a small and very transient increase in cAMP only (Fig. 3). However, combinations of glucagon plus glucose are far more effective than glucose alone, causing a pronounced and sustained elevation of islet cAMP content (Fig. 2). 


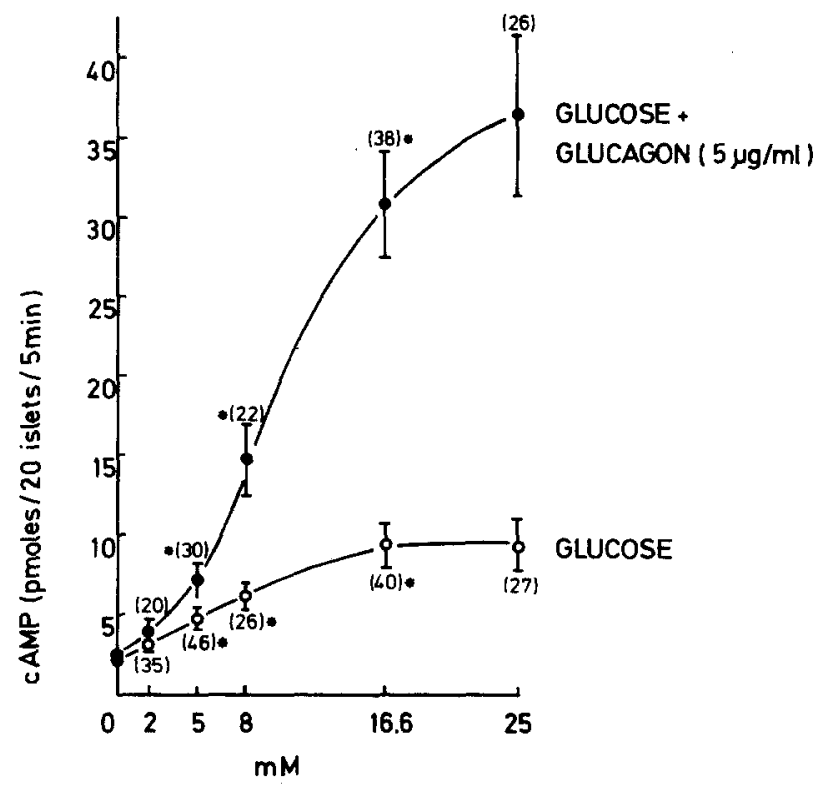

Fig. 2. Dose/response relationship between glucose, with or without glucagon, and cAMP-accumulation in isolated rat pancreatic islets. After a $30 \mathrm{~min}$ preincubation in the presence of $2 \mathrm{mM}$ glucose, batches of 20 islets were incubated for $5 \mathrm{~min}$ in $500 \mu$ l KRB-buffer containing 2; 5; $8 ; 16.6$ or $25 \mathrm{mM}$ glucose with or without glucagon $(5 \mu \mathrm{g} / \mathrm{ml})$. Mean values \pm SEM are shown, with the number of individual observations obtained from 12 to 20 pancreata in parentheses. An asterisk indicates a significant difference from the respective buffer controls $(\mathrm{P}<0.05)$
It is unclear why glucose should be essential for glucagon-induced cAMP-generation in islet tissue. Glucagon is thought to increase cAMP levels in islets by stimulating the adenylate-cyclase system [18-20, 22, 23]. According to hypothetical models, the adenylate cyclase system consists of regulatory units, a transducer and a catalytic unit [29]. The first step in glucagon action seems to be the binding to structure-discriminating receptors (regulatory unit) of the adenylate cyclase system (for review see [29]).

There is no evidence that glucose is necessary for the binding of glucagon to the regulatory unit of the adenylate cyclase system $[24,25]$. It is, however, conceivable that glucose affects the action of glucagon at a step distal to this specific binding site. Signal transduction as well as the catalytic unit seem to be influenced by substances such as $\mathrm{Ca}^{++}, \mathrm{Mg}^{++}$, GTP and ATP [29, 33, 34]. Since the metabolism of $\mathrm{Ca}^{++}$and ATP in islets is affected by glucose [26-28], glucose or a glucose metabolite may play a permissive role for the action of glucagon by modulating signal transduction and/or the catalytic unit.

Accumulation of cAMP in islets is only transient (Figs. 1 and 3) as in many other tissues, where cAMP content falls rapidly after an initial peak [30-32]. This was also seen in perifused islets, where the cAMP content declined 2[15] or 5 min

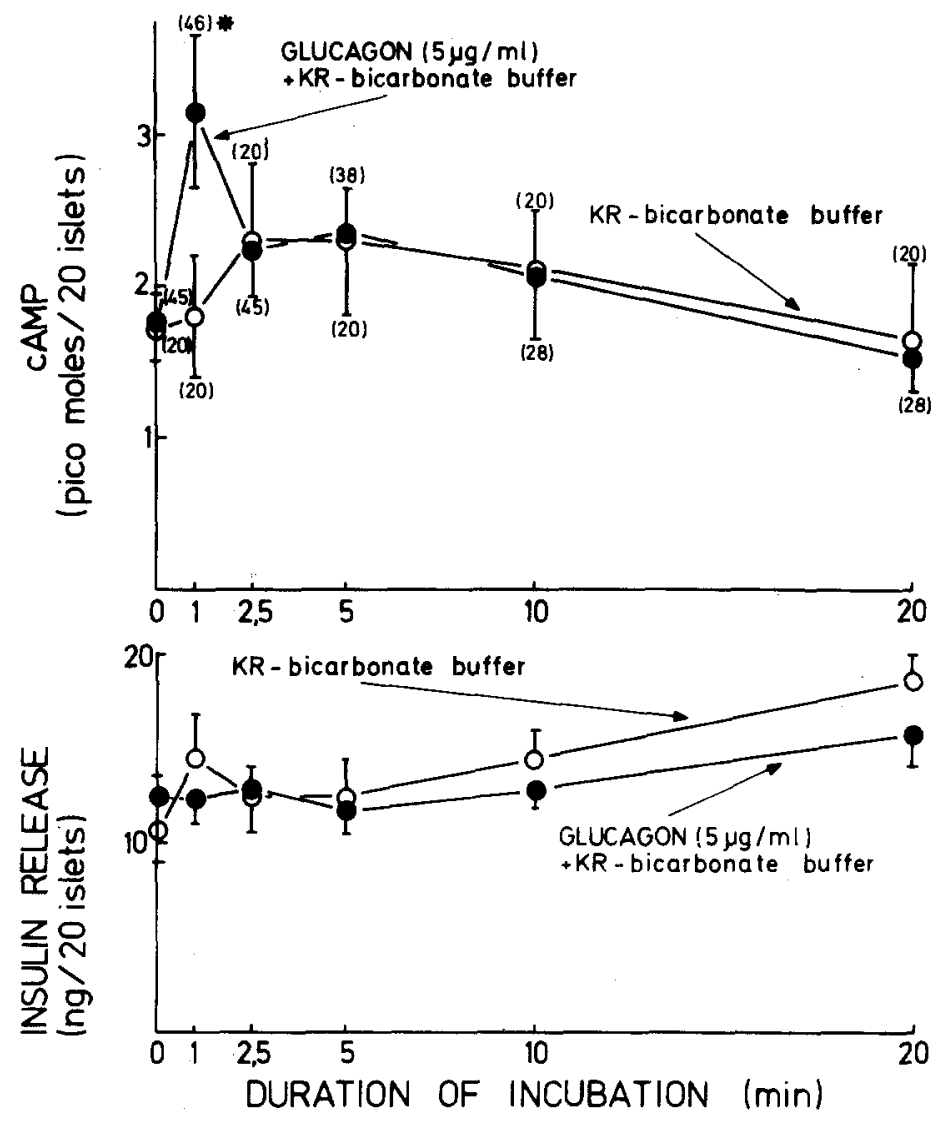

Fig. 3. Rate of insulin release and kinetics of cAMP accumulation in isolated rat pancreatic islets incubated in KRB-buffer with or without glucagon. - After a $30 \mathrm{~min}$ preincubation in the presence of $2 \mathrm{mM}$ glucose islets were incubated for $1,2.5,5,10$ or $20 \mathrm{~min}$ in $500 \mu \mathrm{l} \mathrm{KRB}$-buffer with or without $5 \mu \mathrm{g} / \mathrm{ml}$ glucagon. The CAMP-content of the islets (pmol/20 islets) is shown in the upper panel, the insulin content of the medium in the lower panel of the figure. Mean values \pm SEM are shown, with the number of individual observations obtained from 8 to 16 pancreata in parentheses. The asterisk indicates the only significant difference from the respective buffer control ( $\mathrm{P}$ $<0.02$ ) 
[16] after the start of the perifusion. The decline might be due to accumulation of inhibitory products $[16]$ or to the rising insulin concentration in the incubation medium. Insulin inhibits basal and stimulated adenylate cyclase activity in islets [23] and diminishes the glucose-induced increase in islet cAMP [15]. To what extent the phosphodiesterase system is responsible for the observed decline in islet cAMP content is not known.

The significance of changes in islet cAMP content for the release of insulin remains an open question. Positive correlations between cAMP content and the rate of IRI release after stimulation with secretagogues are usually quoted as evidence that cAMP is mediating the secretory effect. Thus, there is a sigmoidal increase in cAMP levels and in IRI release in response to rising glucose concentrations or to combinations between glucose plus glucagon ([12-17], Fig. 2). The increase in cAMP content and IRI secretion is correlated with time. If cAMP accumulation is only very small, as in the presence of either low glucose concentration (Fig. 2) or of glucagon in the absence of glucose (Fig. 3), IRI release is not stimulated.

However, whether the correlation of cAMP and IRI-release indicates a cause/effect relationship is debatable. The cAMP content in the islets reflects cAMP metabolism only partially, e.g. gives no direct information on turnover rates of cAMP and on the activity of adenylate cyclase or phosphodiesterase in islets. Furthermore, determination of the total cAMP gives no insight into the possible compartmentalisation of cAMP in the B-cells, i.e. in changes in a cAMP pool possibly more closely related to IRI release.

Indeed, there are examples where the content of cAMP does not correlate with the secretion rate of insulin. We observed the highest cAMP content in islets during the first minutes of incubation, when the IRI content in the media was still low. By contrast, at the end of incubation, i.e. when the IRI content in the medium was very high, the cAMP content/islet had returned to baseline values (Fig. 1). In addition, it was recently reported that the ratio of IRI release/cAMP content in islets is smaller during incubation with glucose plus methylxanthines than during incubation with glucose alone $[12,14]$. Thus, the pronounced effect of glucose on IRI release is correlated with a comparatively small increase in the islet's cAMP content. This was taken as evidence that cAMP probably does not mediate the IRI-releasing action of glucose [12], a concept subsequently modified by assuming a dual role of glucose, one involving cAMP and a second operating independently of cAMP [16].
Data available at present indicate that the correlation between cAMP content and rate of IRI release in glucose-stimulated islets is limited. A closer relation seems to exist between the potentiation of glucose-induced IRI-release by glucagon and the glucagon-induced, glucose-mediated increase in the islet cAMP content. Our data thus agree with the concept that glucagon influences IRI release via stimulating the adenylate cyclase system, but the hormone is unable to do so in the absence of glucose. This may be the reason why glucagon is a potentiator rather than an initiator of insulin secretion.

The discussion of the interactions between glucose and glucagon on CAMP-generation and IRI release by B-cells must, however, consider that the percentage of non B-cells in rat islets is relatively high and that glucose affects the release of glucagon $[35,36]$, somatostatin [37] and possibly further islet hormones [38] in addition to the action on IRI release. This complicates the interpretation of the results considerably.

Acknowledgements. The study was supported by the Deutsche Forschungsgemeinschaft (grant Scha 246/2 and Fr 264/4). The skilfull technical assistance of K. Illmer, H. Arends, U. Stauder, H. Wähner and $\mathrm{G}$. Wedemeyer is highly appreciated.

\section{References}

1. Montague, W., Howell, S. L.: Cyclic AMP and the physiology of the islets of Langerhans. In: P. Greengard, G. A. Robinson (eds.): Advances in Cyclic Nucleotide Research, Vol. 6, p. 202-235. New York: Raven Press 1975

2. Malaisse, W.J.: Biochemistry and biophysics of insulin secretion. IV. Participation of the adenylate cyclase system. In: A. Hasselblatt, F.v. Bruchhausen (eds.): Handbook of Experimental Pharmacology, Vol. XXXII/2, p. 131-143. Berlin, Heidelberg, New York: Springer 1975

3. Matschinsky, F.M., Ellerman, J., Stillings, S., Raybaud, F., Pace, C., Zawalich, W.: Hexoses and insulin secretion. In: A. Hasselblatt, F.v. Bruchhausen (eds.): Handbook of Experimental Pharmacology, Vol. XXXII/2, p. 79-114. Berlin, Heidelberg, New York: Springer 1975

4. Malaisse, W. J., Malaisse-Lagae, F., Mayhew, D.: A possible role for the adenylcyclase system in insulin secretion. J.clin. Invest. 46, 1724-1734 (1967)

5. Schauder, P., Ebert, R., Frerichs, H.: 5'-Guanylylimidodiphosphate: A modulator of glucagon-induced insulin release from isolated rat pancreatic islets. Biochem. Biophys. Res. Commun. 67, 701-705 (1975)

6. Schauder, P., Brown, J.C., Frerichs, H., Creutzfeldt, W.: Gastric inhibitory polypeptide: Effect on glucose-induced insulin release from isolated rat pancreatic islets in vitro. Diabetologia 11, 483-484 (1975)

7. Lacy, P. E., Kostianovsky, M.: Method for the isolation of intact islets of Langerhans from pancreas. Diabetes 16, 35-39 (1967) 
8. Schauder, P., Frerichs, H.: Cytochalasin B: Inhibition of glucose-induced insulin release from isolated rat pancreatic islets. Diabetologia 10, 85-87 (1974)

9. Melani, F., Ditschuneit, H., Bartelt, K. M., Friedrich, H., Pfeiffer, E.F.: Über die radioimmunologische Bestimmung von Insulin im Blut. Klin. Wochenschr. 43, 1000-1007 (1965)

10. Gilman, A.G.: A protein binding assay for adenosine 3', $5^{\prime}$-cyclic monophosphate. Proc. Natl. Acad. Sci. USA 67, 305-312 (1970)

11. Schwabe, U., Ebert, R.: Different effects of lipolytic hormones and phosphodiesterase inhibitors on cyclic 3', 5' -AMP levels in isolated fat cells. Naunyn Schmiedebergs Arch. Pharmacol. 274, 287-298 (1972)

12. Charles, M.A., Fanska, R., Schmidt, F. G., Forsham, P.H., Grodsky, G. M.: Adenosine 3', 5'-monophosphate in pancreatic islets: Glucose-induced insulin release. Science 179 , 569-571 (1973)

13. Grill, V., Cerasi, E.: Stimulation by D-glucose of cyclic adenosine $3^{\prime}$ : 5'-monophosphate accumulation and insulin release in isolated pancreatic islets of the rat. J. Biol. Chem. 249, 4196-4201 (1974)

14. Hellman, B., Idahl, L.-A., Lernmark, A., Täljedal, I. B.: The pancreatic $\beta$-cell recognition of insulin secretagogues: Does cyclic AMP mediate the effect of glucose? Proc. Natl. Acad. Sci. USA 71, 3405-3409 (1974)

15. Zawalich, W.S., Karl, R.C., Ferrendelli, J.A., Matschinsky, F. M.: Factors governing glucose induced elevation of cyclic $3^{\prime} 5^{\prime}$-AMP levels in pancreatic islets. Diabetologia 11, 231-235 (1975)

16. Charles, M. A., Lawecki, J., Pictet, R., Grodsky, G. M.: Insulin secretion: Interrelationships of glucose, cyclic adenosine 3',5'-monophosphate and calcium. J. Biol. Chem. 250, 6134-6140 (1975)

17. Charles, M. A., Lawecki, J., Steiner, A.L., Grodsky, G. M.: Cyclic nucleotides in pancreatic islets: Tolbutamide- and arginine-induced insulin release. Diabetes 25, 256-259 (1976)

18. Turtle, J.R., Kipnis, D. M.: An adrenergic receptor mechanism for the control of cyclic $3^{\prime}, 5^{\prime}$-adenosine monophosphate synthesis in tissues. Biochem. Biophys. Res. Commun. 28, 797-802 (1967)

19. Montague, W., Cook, J.R.: The role of adenosine $3^{\prime}: 5^{\prime}$-cyclic monophosphate in the regulation of insulin release by isolated rat islets of Langerhans. Biochem. J. 122, 115-120 (1971)

20. Miller, E. A., Wright, P.H., Allen, D. O.: Effect of hormones on accumulation of cyclic AMP $-{ }^{14} \mathrm{C}$ in isolated pancreatic islets of rats. Endocrinology 91, 1117-1119 (1972)

21. Cooper, R. H., Ashcroft, S. J.H., Randle, P. J.: Concentration of adenosine $3^{\prime}$ : $5^{\prime}$-cyclic monophosphate in mouse pancreatic islets measured by a protein-binding radioassay. Biochem. J. 134, 599-605 (1973)

22. Sussman, K.E., Vaughan, G. D.: Insulin release after ACTH, glucagon and adenosine $3^{\prime} 5^{\prime}$ phosphate (cAMP) in the perfused isolated rat pancreas. Diabetes 16, 449-454 (1967)

23. Kuo, W. N., Hodgins, D. S., Kuo, F. J.: Adenylate cyclase in islets of Langerhans. J. Biol. Chem. 248, 2707-2711 (1973)

24. Rodbell, M., Krans, H. M. J., Pohl, S. L., Birnbaumer, L.: The glucagon-sensitive adenyl cyclase system in plasma mem- branes of rat liver. III. Binding of glucagon: Method of assay and specificity. J. Biol. Chem. 246, 1861-1871 (1971)

25. Rodbell, M., Lin, M. C., Salomon, Y.: Evidence for interdependent action of glucagon and nucleotides on the hepatic adenylate cyclase system. J. Biol. Chem. 249, 59-65 (1974)

26. Hellman, B., Idahl, L. A., Danielsson, A.: Adenosine triphosphate levels of mammalian pancreatic B cells after stimulation with glucose and hypoglycemic sulfonylureas. Diabetes 18, 509-516 (1969)

27. Ashcroft, S. J. H., Weerasinghe, L.C. C., Randle, P. J.: Interrelationship of islet metabolism, adenosine triphosphate content and insulin release. Biochem. J. 132, 223-231 (1973)

28. Malaisse, W. J.: Secretion of insulin. V. Role of cations. In: A. Hasselblatt, F.v. Bruchhausen (Edts.): Handbook of Experimental Pharmacology, Vol.XXXII/2, p.145-155. Berlin, Heidelberg, New York: Springer 1975

29. Rodbell, M., Birnbaumer, L., Pohl, S.L., Krans, H.M.J.: Properties of the adenyl cyclase systems in liver and adipose cells: The mode of action of hormones. Acta Diabetol. Lat. 7 (Suppl. 1), 9-63 (1970)

30. Schwabe, U., Ebert, R., Erbler, H.C.: Adenosine release from isolated fat cells and its significance for the effects of hormones on cyclic 3', 5'-AMP levels and lypolysis. Naunyn Schmiedebergs Arch. Pharmacol. 276, 133-148 (1973)

31. Cramer, H., Lindl, T.: Release of cyclic AMP from rat superior cervical ganglia after stimulation of synthesis in vitro. Nature 249, 380-382 (1974)

32. Stock, K., Thomas, T.: Biphasic effect of the $\alpha$-adrenolytic phentolamine on hormone-stimulated formation of cyclic adenosine $3^{\prime}, 5^{\prime}$-monophosphate in isolated fat cells of rats. Metabolism 24, 277-286 (1975)

33. Maguire, M.E., Sturgill, T.W., Gilman, A. G.: Frustration and adenylate cyclase. Metabolism 24, 287-299 (1975)

34. Levey, G.S.: The glucagon receptor and adenylate cyclase. Metabolism 24, 301-310 (1975)

35. Vance, J.E., Buchanan, K.D., Challoner, R.D., Williams, R. H.: Effect of glucose concentration on insulin and glucagon release from isolated islets of Langerhans of the rat. Diabetes 17, 187-193 (1968)

36. Buchanan, K.D., Mawhinney, W. A. A.: Glucagon release from isolated pancreas in streptozotocin-treated rats. Diabetes 22, 797-800 (1973)

37. Schauder, P., McIntosh, C., Arends, J., Arnold, R., Frerichs, H., Creutzfeldt, W.: Somatostatin and insulin release from isolated rat pancreatic islets stimulated by glucose. FEBS Lett. 68, 225-227 (1976)

38. Larsson, L. I., Sundler, F., Hakanson, R.: Pancreatic polypeptide. A postulated new hormone: Identification of its cellular storage site by light and electron microscopic immunocytochemistry. Diabetologia 12, 211-226 (1976)

Received: September 24, 1976, and in revised form:

January 20,1977

Dr. med. P. Schauder

Medizinische Universitätsklinik

Humboldtallee 1

D-3400 Göttingen

Federal Republic of Germany 